\title{
Optimisation of Rhamnolipid: A New Age Biosurfactant from Pseudomonas aeruginosa MTCC 1688 and its Application in Oil Recovery, Heavy and Toxic Metals Recovery
}

Pathaka AN ${ }^{1}$ and Pranav H Nakhate ${ }^{2 *}$

${ }^{1}$ Research Dean and Head of Institution, Amity Institute of Biotechnology, Amity University Rajasthan, India

${ }^{2}$ Biochemical Engineering Scholar Jaipur, Amity Institute of Biotechnology, Amity University Rajasthan, India

\begin{abstract}
Rhamnolipid is a new age biosurfactant, commonly produced biotechnologically with Pseudomonas aeruginosa in batch cultivations whereas novel substrates like karanja oil and soybean oil cake were employed, giving yield of 3.609 $\mathrm{gm} /$ lit of rhamnolipid, which shows effective and enhanced production of rhamnolipid, compared to other vegetable oil as a carbon sources, mentioned in the literature, at optimised $\mathrm{pH}$ of 7.0 and optimised substrate concentration at $3.0 \%$. The optimum yield in terms of substrate was observed as $3.609 \mathrm{gm} /$ lit of rhamnolipid produced per $5.255 \mathrm{ml}$ of oil consumed, while yield in terms of biomass was observed as $3.609 \mathrm{gm} / \mathrm{lit}$ of rhamnolipid produced per $2.5 \mathrm{gm}$ of dry biomass. The chloroform:methanol (2:1) extraction system was found to be the best solvent extraction system, where $83 \%$ of the rhamnolipid was recovered. The Rhamnolipid was successfully applied for the heavy and toxic metals recovery, where rhamnolipid reduces heavy metal concentration to $73 \%, 65 \%$ and $71 \%$ for $\mathrm{FeCl}_{3}, \mathrm{ZnSO}_{4}$ and $\mathrm{Pb}\left(\mathrm{NO}_{3}\right)_{2}$ respectively, while $43 \%$ in the case of toxic metal i.e. NaF. The produced rhamnolipid was found efficient in recovering $31 \%$ no-edible oil from oil sludge.
\end{abstract}

Keywords: Rhamnolipid; Karanja oil; Soybean oil cake; Heavy metal; Toxic metal; Oil recovery

\section{Introduction}

\section{Biosurfactants}

"Biosurfactants" are microbially produced, structurally diverse group of surface active biochemical molecules. The huge diversity of biosurfactants makes them an interesting moiety for application in many areas including agriculture, health care, public health, food, waste utilization, and environmental pollution control, like degradation of hydrocarbons present [1].

Microbially produced biosurfactants are adequate to fulfil many of the roles for which petrochemical and oleochemical surfactants are currently used [2]. The global market for surfactants is approximately 15 million tonnes per annum with a global average annual growth of approximately 3 per cent [3]. As demand on "crude oil" supplies increases the use of "sustainable biosurfactants" instead of petrochemically derived surfactants becomes more fascinating.

Biosurfactants often have interesting characteristics not possessed by petrochemical or oleochemical surfactants, like their application in "pharmaceuticals", "bioremediation", "food processing", nevertheless, for this to happen actually in an industrial scale, there needs to be the improved development of fermentation processes and downstream separation techniques for effective biosurfactant production $[1,4,5]$. Downstream separation techniques require deep knowledge, as they contribute approximately $60 \%$ to the total cost of biosurfactant production [6]. Current research and industrial interest rests in many biosurfactants, including "surfactin" obtained from Bacillus subtilis, hydrophobin proteins from various filamentous fungi such as Schizophyllum commune and Trichoderma reesei, and rhamnolipids from Pseudomonas aeruginosa $[7,8]$.

\section{Rhamnolipid}

Rhamnolipids are "anionic glycolipids" consisting of "L-rhamnose" and " $\beta$-hydroxy fatty acids" produced by $P$. aeruginosa strain. The hydrophilic rhamnose moiety is attached by a glycosidic linkage to the lipid fatty acid tail. Rhamnolipids are generated as a mixture of different rhamnolipids $[2,6,9]$.

It has been explained that, the rhamnolipid can be produced from various microorganism, but the Pseudomonas aeruginosa is found to be the most effective and prominent strain responsible for the production of rhamnolipid $[9,10]$. Rhamnolipid is one of the most important biosurfactant, as it can used for the various purposes. The problems, that hinder the bulk production of rhamnolipid are, the use of cheap raw materials, and effective downstreaming. Various journals reported the use of vegetable oils, waste oil etc. as a carbon source. Some other journals reported use of cheap whey, or molasses as a carbon source [11].

For the production of rhamnolipid, the search of low cost source ended at the plant derived oil, i.e. karanja. Nowhere in the literature, is it reported so far, that uses karanja oil as a source for the production of rhamnolipid. Karanja oil contains more amounts of fatty acids, which can be made available to the microorganism easily, and high production of rhamnolipid can be expected. Waste soybean oil cake is the complete waste, and generally used as an animal feed. Hence, use of such oil cake will definitely decrease the bulk production cost $[12,13]$

*Corresponding author: Pranav H Nakhate, Biochemical Engineering Scholar Amity University Rajasthan, 14-Gopal Bari, Ajmer Road, Jaipur 302001, India, Tel: 950-357-3593; E-mail: pran.nakhate@yahoo.com

Received April 20, 2015; Accepted May 22, 2015; Published May 27, 2015

Citation: Pathaka AN, Nakhate PH (2015) Optimisation of Rhamnolipid: A New Age Biosurfactant from Pseudomonas aeruginosa MTCC 1688 and its Application in Oil Recovery, Heavy and Toxic Metals Recovery. J Bioprocess Biotech 5: 229 doi:10.4172/2155-9821.1000229

Copyright: @ 2015 Pathaka AN, et al. This is an open-access article distributed under the terms of the Creative Commons Attribution License, which permits unrestricted use, distribution, and reproduction in any medium, provided the original author and source are credited. 
(Figure 1).

Many researchers reported that, the rhamnolipid is late-growth phase product, and its production increases in the stationary phase. The results obtained from our research supports the findings of such researchers like SD Wadekar et al. [14]. From the graphs, explained later in the report, it was crystal clear that, rhamnolipid production starts at the late growth phase, indicating that, microorganisms utilises most of the carbon sources available first, and then produces product. The sudden increase in production was observed during the stationary phase. The media used contains less amount of phosphorus source in order to stringent the growth condition, hence ultimately microorganism growth ceases, and the culture enters into the stationary phase and high production can be achieved [15].

The production costs of biosurfactants, compared to synthetic compounds, are at least 50 times higher, on the surfactant market. It is estimated that the production costs of rhamnolipids produced in 25$200 \mathrm{~m}^{3}$ scale is at about $6-25 \mathrm{US} \$ / \mathrm{kg}$. Compared with petrochemical bulk surfactants like ethoxylates or alkyl polyglycosides, ranging at 1-3 US $\$ / \mathrm{kg}$, rhamnolipids are not competitive in this field [3].

\section{Material and Methodology}

\section{Inoculum preparation procedure}

First step in the inoculum preparation is the culture revival. The Pseudomonas aeruginosa MTCC 1688 mother culture was revived according to the standard protocol given in the various microbiological journals. The mother culture was carefully inoculated into the freshly prepared nutrient broth, strictly under aseptic conditions in vertical laminar air flow.

After the successful microbial transfer, the $100 \mathrm{ml}$ shake flask, containing nutrient broth was kept in Incubator for $24 \mathrm{hrs}$ to grow the microorganisms. After 24 hrs, a loop full of inoculation from nutrient broth was taken and spread over the nutrient agar plate using quadrant technique. Four nutrient agar plates were kept at $4^{\circ} \mathrm{C}$ for further use.

\section{Gram staining procedure}

In order to check the Gram's nature of the microorganism, Gram staining was performed. The drop wise addition of crystal violet stains the bacterial in blue colour, while Gram's iodine is used to fix the crystal violet stain. Decolourisation occurs with addition of $70 \%$ ethanol, followed by addition of counter stain Safranin, which stains bacteria in pink colour.

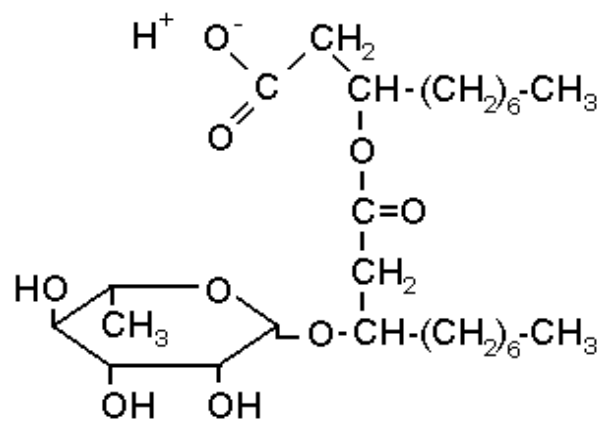

Figure 1: Rhamnolipid structure.

\section{Shake flask cultivation}

Cultivation experiment was carried out in $500 \mathrm{ml}$ shake flask. As discussed in literature review, cheap carbon source had to use, hence, plant oil karanja was used, as it is a cheap hydrocarbon source. Soybean oil cake is also a waste, which is used as another hydrocarbon source. Glucose is used as a standard carbon source. The phosphate regulation was carried out by adapting minimal salt media (MSM) composition from Cameotra et al. [16]. Carbon to the nitrogen ratio i.e. C:N was maintained 20, by using $\mathrm{NaNO}_{3}$ as a nitrogen source.

The optimization strategy was carried out by varying the percentage of carbon source used. $1 \%, 3 \%$ and $5 \%$ of carbon sources mentioned above were examined for the highest production of rhamnolipid. At the same time, $\mathrm{pH}$ of the media was varied using $0.1 \mathrm{~N} \mathrm{HCl}$ and $0.1 \mathrm{~N}$ $\mathrm{NaOH}$. Shake flask was operated at $\mathrm{pH} 5, \mathrm{pH} 7$ and $\mathrm{pH} 9$ respectively after the Carbon source and its percentage optimisation.

The optimum carbon source, its concentration and optimum $\mathrm{pH}$ was calculated for highest rhamnolipid production. The other operating conditions, like temperature, agitation speed were properly maintained. The operating temperature was set $30^{\circ} \mathrm{C}$ and agitation speed was maintained $150 \mathrm{rpm}$ in remi orbital shaker-incubator. During the cultivation period, biomass concentration, substrate concentration and rhamnolipid concentration were checked every after $24 \mathrm{hrs}$. After obtaining higher productivity, the cultivation days were calculated and the scale up was done (Figure 2).

\section{Determination of biomass concentration}

There are various methods which can be used for the determination of biomass. The cell dry mass was measured and calculated. The technique was carried out through following steps:

$10 \mathrm{ml}$ culture broth was taken

$\downarrow$

Centrifugation carried out at $8000 \mathrm{rpm}$ for $10 \mathrm{~min}$.

$\downarrow$

Pellet was collected and suspended in $0.9 \%$ saline tube $\downarrow$

Proper vortexed in order to re-suspend solid particles $\downarrow$

Allowed to settle the solid particles

$$
\downarrow
$$

Filtered and dried the sample in order to measure dry mass

\section{Determination of glucose concentration}

Glucose is the simplest carbon source, utilised by almost all the microbes for their growth. The glucose decreases with the course of time, hence its concentration over the course of time is required for the calculations of yield of the product i.e. rhamnolipid product formed

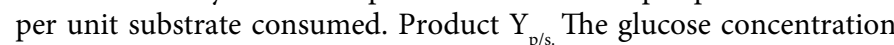
was measured by using standard DNSA curve.

DNSA method was invented by Miller in 1959. DNSA method is basically used to detect free aldehyde groups present in the sugar, i.e. to detect reducing sugar. Oxidation of aldehyde group results into the formation of carboxyl group, which then reduce to 3-amino, 5-nitro 
Citation: Pathaka AN, Nakhate PH (2015) Optimisation of Rhamnolipid: A New Age Biosurfactant from Pseudomonas aeruginosa MTCC 1688 and its Application in Oil Recovery, Heavy and Toxic Metals Recovery. J Bioprocess Biotech 5: 229 doi:10.4172/2155-9821.1000229

Page 3 of 14

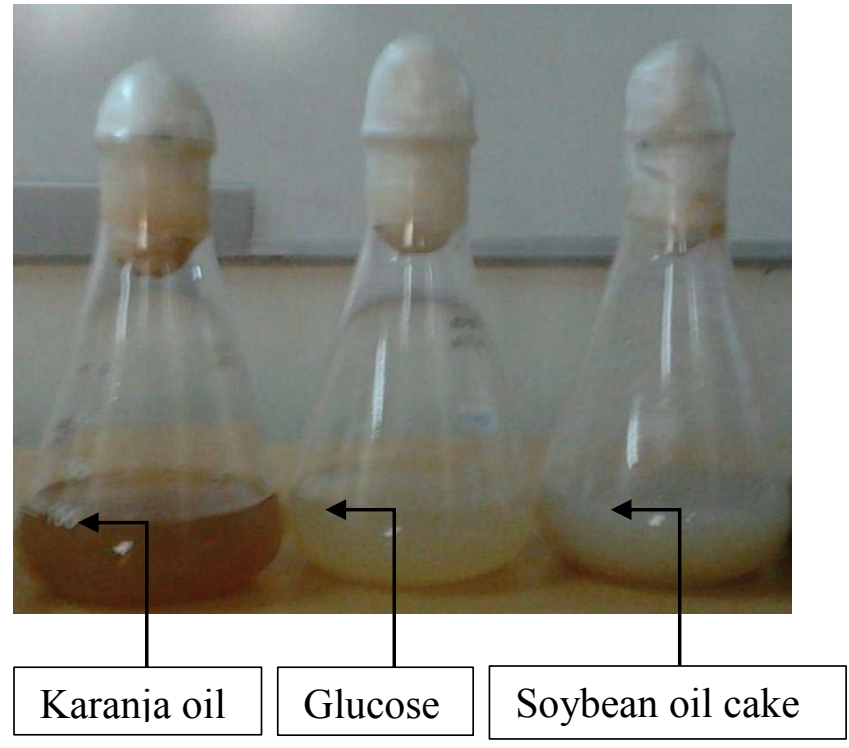

Figure 2: Shake flask study.

\begin{tabular}{|c|c|c|c|c|c|}
\hline $\begin{array}{c}\text { Tube } \\
\text { No. }\end{array}$ & $\begin{array}{c}\text { Amount } \\
\text { of stock } \\
\text { added }\end{array}$ & $\begin{array}{c}\text { Amount of } \\
\text { D/W added }\end{array}$ & $\begin{array}{c}\text { Final } \\
\text { volume }\end{array}$ & Dilution & Concentration \\
\hline 1 & $0 \mathrm{ml}$ & $10 \mathrm{ml}$ & $10 \mathrm{ml}$ & 0 & $0 \mathrm{mg} / \mathrm{ml}$ \\
\hline 2 & $0.25 \mathrm{ml}$ & $9.75 \mathrm{ml}$ & $10 \mathrm{ml}$ & $1: 40$ & $2.5 \mathrm{mg} / \mathrm{ml}$ \\
\hline 3 & $0.5 \mathrm{ml}$ & $9.5 \mathrm{ml}$ & $10 \mathrm{ml}$ & $1: 20$ & $5 \mathrm{mg} / \mathrm{ml}$ \\
\hline 4 & $1 \mathrm{ml}$ & $9 \mathrm{ml}$ & $10 \mathrm{ml}$ & $1: 10$ & $10 \mathrm{mg} / \mathrm{ml}$ \\
\hline 5 & $2 \mathrm{ml}$ & $8 \mathrm{ml}$ & $10 \mathrm{ml}$ & $1: 5$ & $20 \mathrm{mg} / \mathrm{ml}$ \\
\hline 6 & $5 \mathrm{ml}$ & $5 \mathrm{ml}$ & $10 \mathrm{ml}$ & $1: 2$ & $50 \mathrm{mg} / \mathrm{ml}$ \\
\hline 7 & $10 \mathrm{ml}$ & $0 \mathrm{ml}$ & $10 \mathrm{ml}$ & $1: 1$ & $100 \mathrm{mg} / \mathrm{ml}$ \\
\hline
\end{tabular}

Table 1: Preparation of dilutions for glucose standard curve using DNSA method.

salicylic acid in presence of DNSA, which is calculated.

The stock solution of $100 \mathrm{mg} / \mathrm{ml}$ was prepared and further dilutions were made as mentioned below. $3 \mathrm{ml}$ of DNSA solution was added to $3 \mathrm{ml}$ of test sample and mixture was heated at $90^{\circ} \mathrm{C}$ for $15 \mathrm{~min}$. Then, $1 \mathrm{ml}$ of potassium-sodium tartarate i.e. Rochelle salt was added to solubilise the colour. The mixture was then allowed to cool down and $\mathrm{OD}$ was measure on colorimeter at $540 \mathrm{~nm}$.

\section{Determination of free fatty acid content}

Another important substrates used for the rhamnolipid production, were karanja oil and soybean oil cake. Both the substrates are plant originated and contains high amount of unsaturated fatty acid, i.e. oleic acid. Hence free fatty acid content in terms of oleic acid was calculated. The hexane was added in order to extract oil residues from broth culture (Table 1).

The procedure was followed as given below:

$10 \mathrm{ml}$ culture broth was taken

Centrifugation carried out at $8000 \mathrm{rpm}$ for $10 \mathrm{~min}$

Pellet was collected and suspended in $0.9 \%$ saline tube
Proper vortexed in order to re-suspend solid particles<smiles>[AlH2]</smiles>

Allowed to settle the solid particles

Filtered and dried the sample in order to measure dry mass

The titration readings were noted down and acid value was calculated from the equation,

$$
\text { Acid Value }=\frac{(56.1 \times \text { Burette reading } \times \text { Normality of } \mathrm{KOH})}{\text { Weight in grams }}
$$

\section{Rhamnolipid detection [14]}

Rhamnolipid detection was carried out using orcinol reagent The culture broth was centrifuged at $8000 \mathrm{rpm}$ for $15 \mathrm{~min}$ and the supernatant as collected. The supernatant was then treated with orcinol reagent, containing concentrated $\mathrm{H}_{2} \mathrm{SO}_{4}$ which causes L-rhamnose moiety to separate it out from lipid moiety and the L-rhamnose concentration can be calculated. This is the indirect way of detection of rhamnolipid, as pure rhamnolipid was not available.

Orcinol Reagent was produced by adding $53 \% \mathrm{H}_{2} \mathrm{SO}_{4}$ solution to $0.19 \%$ orcinol solution. For each $1 \mathrm{ml}$ sample, $9 \mathrm{ml}$ orcinol reagent was summed. The formed mixture was then heated at $70^{\circ} \mathrm{C}$ for $30 \mathrm{~min}$. and then allowed to cool down for $30 \mathrm{~min}$. The optical density was

\begin{tabular}{|c|c|c|c|c|c|}
\hline Tube No & $\begin{array}{c}\text { Amount of } \\
\text { stock added }\end{array}$ & $\begin{array}{c}\text { Amount of } \\
\text { D/W added }\end{array}$ & $\begin{array}{c}\text { Final } \\
\text { volume }\end{array}$ & Dilution & Concentration \\
\hline 1 & $0 \mathrm{ml}$ & $10 \mathrm{ml}$ & $10 \mathrm{ml}$ & 0 & $0 \mathrm{mg} / \mathrm{ml}$ \\
\hline 2 & $0.25 \mathrm{ml}$ & $9.75 \mathrm{ml}$ & $10 \mathrm{ml}$ & $1: 40$ & $0.25 \mathrm{mg} / \mathrm{ml}$ \\
\hline 3 & $0.5 \mathrm{ml}$ & $9.5 \mathrm{ml}$ & $10 \mathrm{ml}$ & $1: 20$ & $0.5 \mathrm{mg} / \mathrm{ml}$ \\
\hline 4 & $1 \mathrm{ml}$ & $9 \mathrm{ml}$ & $10 \mathrm{ml}$ & $1: 10$ & $1 \mathrm{mg} / \mathrm{ml}$ \\
\hline 5 & $2 \mathrm{ml}$ & $8 \mathrm{ml}$ & $10 \mathrm{ml}$ & $1: 5$ & $2 \mathrm{mg} / \mathrm{ml}$ \\
\hline 6 & $5 \mathrm{ml}$ & $5 \mathrm{ml}$ & $10 \mathrm{ml}$ & $1: 2$ & $50 \mathrm{mg} / \mathrm{ml}$ \\
\hline 7 & $10 \mathrm{ml}$ & $0 \mathrm{ml}$ & $10 \mathrm{ml}$ & $1: 1$ & $10 \mathrm{mg} / \mathrm{ml}$ \\
\hline
\end{tabular}

Table 2: Preparation of dilutions for L-rhamnose standard curve using orcino reagent.

\begin{tabular}{|c|c|c|}
\hline System used & Phase & $\begin{array}{c}\text { O.D. at 540 } \\
\mathbf{n m}\end{array}$ \\
\hline \multirow{2}{*}{ Ethyl acetate } & Organic phase & 0.41 \\
\hline & Aqueous phase & 0.15 \\
\hline $\begin{array}{c}\text { Chloroform: } \\
\text { Methanol }\end{array}$ & Organic phase & 0.48 \\
\cline { 2 - 3 } & Aqueous phase & 0.12 \\
\hline
\end{tabular}

Table 3: Solvent extraction readings.

\begin{tabular}{|c|c|}
\hline Process used & O.D. at $\mathbf{5 4 0} \mathbf{~ n m}$ \\
\hline $\begin{array}{c}\text { Column } \\
\text { chromatography }\end{array}$ & 0.51 \\
\hline $\begin{array}{c}\text { Rotary vacuum } \\
\text { chromatography }\end{array}$ & 0.48 \\
\hline
\end{tabular}

Table 4: Different process readings. 


\begin{tabular}{|c|c|c|}
\hline S.No. & $\begin{array}{c}\text { Stretching } \\
\text { present }\end{array}$ & $\begin{array}{c}\text { Wavelength } \\
\left(\mathbf{( c m}^{-1}\right)\end{array}$ \\
\hline 1 & $\mathrm{C}-\mathrm{H}$ & 2930.18 \\
\hline 2 & $\mathrm{C}-\mathrm{H}$ & 2856.55 \\
\hline 3 & $\mathrm{C}=\mathrm{O}$ & 1734.35 \\
\hline 5 & $\mathrm{CH} 3$ & 1401.17 \\
\hline 6 & $\mathrm{C}-\mathrm{H} / \mathrm{O}-\mathrm{H}$ & 1384.98 \\
\hline 7 & deform & 1315.45 \\
\hline 8 & OH deform & 1041.63 \\
\hline 9 & C-H deform & 874.07 \\
\hline
\end{tabular}

Table 5: Structural analysis of rhamnolipid using FTIR.

then measured at $520 \mathrm{~nm}$. The standard L-rhamnose $10 \mathrm{mg} / \mathrm{ml}$ stock solution was prepared (Table 2).

\section{CTAB agar method}

CTAB is the cetyl trimethyl ammonium bromide method. This is also called methyl assay for rhamnolipid detection. Concentration of "anionic surfactant" from the mixture of solution can be dictated. CTAB, being "cationic surfactant", bind with the rhamnolipid, which is "anionic surfactant", forming insoluble ion precipitation. This "insoluble ion precipitation" was detected by appearance of 'dark blue' colour on 'light' background (Table 3).

The CTAB agar was prepared by using components mentioned in tables 4 and 5. After autoclaving, petri-plates were poured and allowed to get solidified. After solidification, agar gel was punctured at proper positions using borer, and culture broth supernatant was added into the well using micropipette. The plate was then kept for the $24 \mathrm{hrs}$ incubation and the precipitation zone around the hole were observed.

\section{Production scale up}

Production scale up was done by moving from shake flask to fermenter. For the scale of the production, 2 litre fermenter was used. The important operating conditions which were chosen include, Agitation speed, which was maintained $150 \mathrm{rpm}$. The temperature was maintained $35^{\circ} \mathrm{C}$ throughout. Aeration rate was maintained $0.8 \mathrm{vvm}$ and $\mathrm{pH}$ was kept 7 throughout the process.

Before sterilisation, all the probes and Heating jacket was removed properly. All the filters and a sampling port were taken out and washed properly with alcohol. All the reactor assembly was washed neatly through water and then wiped with alcohol. The reactor assembly was then filled with 1.4 litres of fermentation media, mentioned in table 4. Then, the reactor assembly along with the fermentation media was autoclaved for $45 \mathrm{~min}$ at $20 \mathrm{lbs}$ pressure. After the successful sterilisation, the assembly was allowed to cool down (Figure 3).

After cooling down, the fermenter was then inoculated with seed media, prepared already. The $100 \mathrm{ml}$ Seed media was firstly prepared to grow the $10 \%$ microbes, to give them desired environment. In the middle of the exponential phase, this seed media was transferred aseptically to the fermenter. For the preparation of Seed media, minimal salt media was used.

After the successful transfer of seed media, all the probes and filters were assembled to the reactor. For regulation of $\mathrm{pH}$ during the fermentation course, $0.1 \mathrm{M} \mathrm{H}_{2} \mathrm{SO}_{4}$ and $0.1 \mathrm{~N} \mathrm{NaOH}$ were prepared, and attached to the reactor. The reactor was then started and operated for continuous 7 day. From starting the fermenter, after every $24 \mathrm{hrs,}$ sampling was done.

\section{Down streaming of product}

Down streaming is very important aspect in the fermentation process. The down streaming process was followed as me mentioned below.

\section{Solvent extraction}

First important step in the down streaming of rhamnolipid fermentation was solvent extraction. For the solvent extraction method, two different solvent systems were used, including ethyl acetate and chloroform:methanol system.

The solvent extraction scheme is shown below:

Culture broth$$
\downarrow
$$

Treatment with hexane in case of oil as a substrate

$$
\downarrow \leftarrow \text { RL detection through orcinol method }
$$

Centrifugation

$\downarrow$

Collect supernatant

$\downarrow$

Acid precipitation with $0.6 \mathrm{M} \mathrm{HCl}, \mathrm{pH} 2$

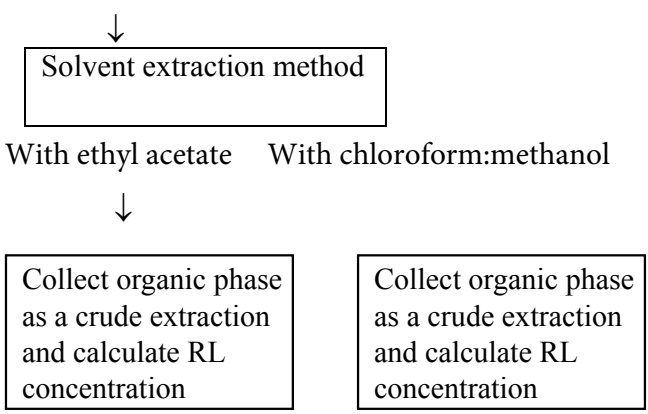

For ethyl acetate solvent system, ethyl acetate:extract ratio was used 1:1, while using chloroform:methanol:extract, 2:1:1 ratio was used. The extraction efficiency and partition coefficient was also calculated for both the systems by calculating the rhamnolipid concentration present in the organic phase.

\section{Chromatography}

Chromatography is one of the major down streaming technique, which purifies rhamnolipid. Paper chromatography was used as an analytical technique, to calculate the retention factor, i.e. $\mathrm{R}_{\mathrm{f}}$ value, while another chromatography, i.e. column chromatography was performed to purify the rhamnolipid. 


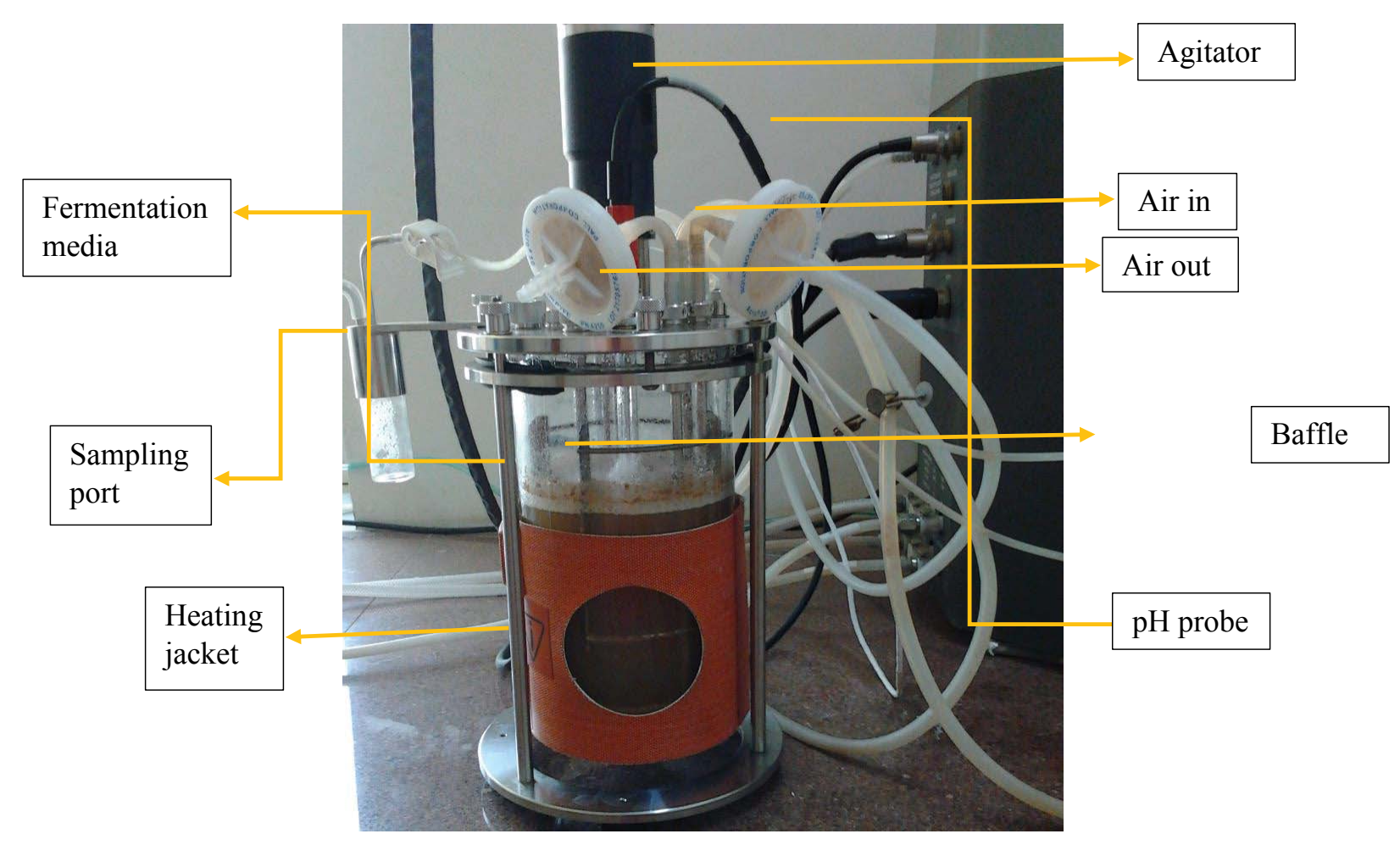

Figure 3: New Brunswick fermenter of 2 lit. capacity.

Paper chromatography: For paper chromatography, the mobile phase used was chloroform:methanol in ratio 2:1. Chromatography paper was marked initially for the sample loading. The sample was loaded at the marking position. The paper was then put into the chromatography jar. After some time, the sample runs on the chromatograph paper in up-ward position, leaving a mark. Hence, the distance travelled by sample to the mobile solvent was calculated.

Column chromatography: Column chromatography was performed with using silica-60 as a packing material or stationary phase. The silica gel-60 was packed tightly under the column. Primary cleaning was done by eluting the methanol from the column. As soon as the methanol was completely eluted, the crude sample was run in a column along with mobile phase. The mobile phase used was chloroform:methanol in 3:2 ratios. The methanol in the mobile phase was used to remove the hydrophobic impurities. Hence, the light brown coloured sample, which was eluted after the dark brown coloured sample, was collected and rhamnolipid concentration was measured.

\section{Rotary vacuum evaporator}

The concentrated product was collected by using the rotary vacuum evaporator (RVE). The collected crude sample was loaded in the round bottom flask of the rotary vacuum evaporator, integrated with vacuum system. The flask was rotated at the speed of $5 \mathrm{rpm}$, and the temperature was set $70^{\circ} \mathrm{C}$, in order to evaporate the water content from the sample, using integrated vacuum. The concentrated sample was then analysed, using FTIR technique.

\section{Emulsification index $[9,10]$}

The emulsion index was calculated in order to check the capacity of formation of emulsion by rhamnolipid. The emulsion index was calculated after 24 hours; hence it is also called $\mathrm{E}_{24}$. Emulsion index was measured in percentage by diving the height of the emulsion to the total height of the mixture. The followed procedure is described below.

$6 \mathrm{ml} \mathrm{D} / \mathrm{W}+2 \mathrm{ml}$ immersion oil<smiles>[AlH2]</smiles>

The sample was vortexed for $10 \mathrm{~min}$

$$
\downarrow
$$

The mixture was allowed to settle down

$$
\downarrow
$$

$2 \mathrm{ml}$ crude rhamnolipid sample was added

$$
\downarrow
$$

Again the sample was vortexed for $10 \mathrm{~min}$ and settled for $24 \mathrm{hrs}$

Emulsion was observed

\section{Emulsion index stability $[10,15]$}

The same procedure as described for the emulsion index was carried out for emulsion index stability test. The only difference with the previous technique is that, the crude rhamnolipid was kept at various temperatures and various $\mathrm{pH}$. Rhamnolipid was kept at $4^{\circ} \mathrm{C}$, $30^{\circ} \mathrm{C}$ and $80^{\circ} \mathrm{C}$ for around $30 \mathrm{~min}$ and the above procedure was carried out. Similarly, rhamnolipid was kept at $\mathrm{pH} 3, \mathrm{pH} 7$ and $\mathrm{pH} 9$ for 30 
Citation: Pathaka AN, Nakhate PH (2015) Optimisation of Rhamnolipid: A New Age Biosurfactant from Pseudomonas aeruginosa MTCC 1688 and its Application in Oil Recovery, Heavy and Toxic Metals Recovery. J Bioprocess Biotech 5: 229 doi:10.4172/2155-9821.1000229

Page 6 of 14

minutes, and its emulsification index was calculated.

\section{Oil spray assay $[16,17]$}

Another important, but simple technique for the detection of emulsion capacity of rhamnolipid is oil spray assay. The following procedure was carried for the same.

$20 \mathrm{ml} \mathrm{D} / \mathrm{W}$ was poured in petri plate

\section{$\downarrow$}

Immersion oil drop was added on the same $\mathrm{D} / \mathrm{W}$

$$
\downarrow
$$

Rhamnolipid of $200 \mu \mathrm{l}$ was added on the immersion drop

$$
\downarrow
$$

Emulsion formation was observed

\section{Heavy and toxic metal recovery $[18]$}

The three major heavy metals along with the one toxic metal were recovered from the solution prepared. Three important heavy metals used were, $\mathrm{Pb}\left(\mathrm{NO}_{3}\right)_{2}, \mathrm{ZnCl}, \mathrm{FeCl}_{3}$ The toxic metal recovered was $\mathrm{NaF}$. The standard concentration of heavy metal produced was $100 \mathrm{mg} / \mathrm{ml}$. The recovery procedure is given below for the $10 \mathrm{ml}$ of the sample used each (Figure 4).

Standard metal conc. of $10 \mathrm{mg} / \mathrm{ml}$ was taken $9 \mathrm{ml}$ in test tube

$$
\downarrow
$$

$1 \mathrm{ml}$ crude rhamnolipid was added in the sample

$$
\downarrow
$$

The mixture was vortexed and allowed to settle for 2 hours

$$
\downarrow
$$

The mixture was filtered through Whatman filter paper

The weight of Whatman filter paper before and after the filtration was measured

The percentage of efficiency of removal of metals i.e. $\eta$ were calculated as,

$$
\eta=\frac{(\text { Initial heavy metal }- \text { Final heavy metal })}{\text { Initial metal concentration }} \times 100
$$

\section{Oil recovery $[17,19]$}

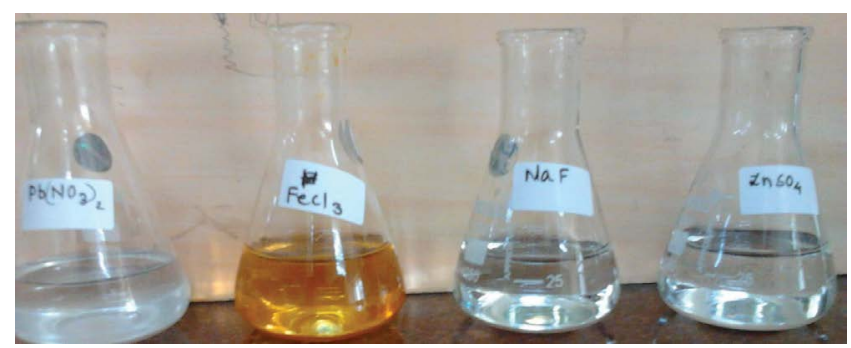

Figure 4: Standard concentration of metal.
Rhamnolipid is very efficient in the oil recovery from oil sludge. The efficiency rhamnolipid for oil recovery was observed from the following protocol.

Components were mixed properly

$$
\downarrow
$$

$10 \mathrm{ml}$ of immersion oil mixed with hot dry sand

$$
\downarrow
$$

$10 \mathrm{ml}$ crude rhamnolipid was added

$$
\downarrow
$$

The whole mixture was vortexed for $10 \mathrm{~min}$ and allowed to settle for $5 \mathrm{~min}$

Whole mixture was centrifuged at $6000 \mathrm{rpm}$ for $20 \mathrm{~min}$

$$
\downarrow
$$

Different layers were observed, including oil emulsion

\section{Results}

Pseudomonas aeruginosa MTCC 1688 strain was successfully revived under the aseptic conditions. The green coloured pigment formation was observed, after $48 \mathrm{hrs}$ of microbial inoculation, indicating presence of Pseudomonas aeruginosa. The strain was then identified using Gram staining procedure (Figures 5 and 6).

\section{Gram staining}

The pink coloured and rod shaped microorganisms were observed under the oil-immersion $100 \times$ lens of the microscope. Hence, gram staining procedure shows Gram-negative nature of $P$. aeruginosa (Graphs 1 and 2).

\section{Shake flask cultivation}

Shake flask optimisation study was carried out using 3 different substrates, i.e. glucose, karanja oil and soybean oil cake. The rhamnolipid production during the course of fermentation was determined by L-rhamnose standard curve. The equation of the straight line was obtained as, $y=0.1712 x+0.0042$ (Graphs 3-5).

After analysing above experimentation, It has been observed that, $3 \%$ concentration of a substrate is efficient in rhamnolipid production. Hence, taking $3 \%$ substrate concentration, the experimentation for $\mathrm{pH}$ optimisation was carried out (Graphs 6-8).

After the shake flask studies, the data was analysed for higher rhamnolipid production, at a different substrates, their concentration and $\mathrm{pH}$. After the successful data analysis of shake flask, the production study was carried out in 2 litre New-Brunswick fermenter, applying optimum conditions from shake flask (Figures 7-10) (Graph 9).

\section{Fermentation studies}

Confirmation of rhamnolipid production: Retention factor, i.e. $\mathrm{R}_{\mathrm{f}}$ value $=5.3 / 10=0.53$

\section{Solvent extraction}

Ethyl acetate:extract ratio was used 2:1 for the extraction, and chloroform:methanol:extract ratio used was 2:1:1 (Figures 11-13) (Tables 3-5). 

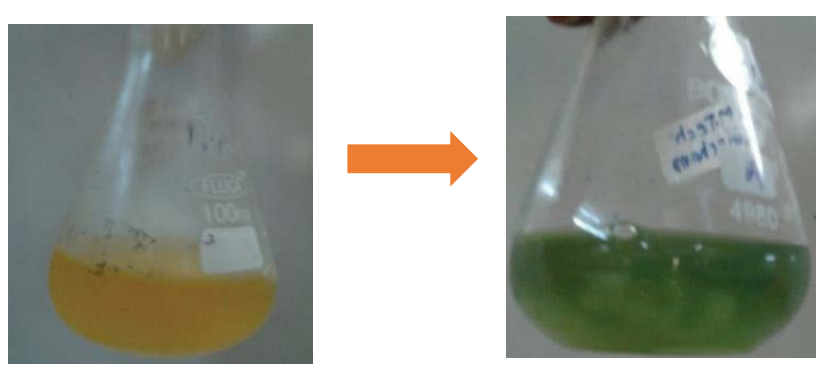

Figure 5: Change of color of $P$. aeruginosa inoculated nutrient broth after $48 \mathrm{hrs}$

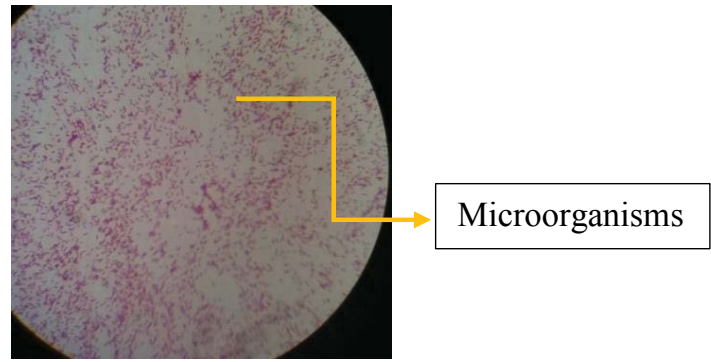

Figure 6: Gram staining.

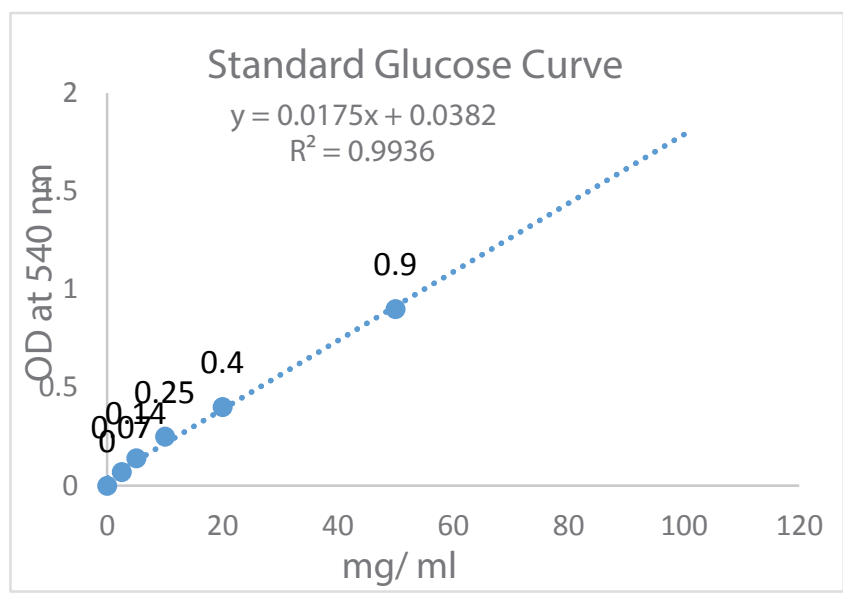

Graph 1: Standard glucose curve.

\section{Structural analysis using FTIR}

The FTIR spectrum analysis of the rhamnolipid, produced from Pseudomonas aeruginosa MTCC 1688 on $3 \%$ soybean oil cake as a substrate, is given below [9] (Table 6).

The data obtained was compared with the literature present, as well as standard spectrum data available, and found that, almost same stretching and deforms were observed.

\section{Emulsification index}

The emulsification index is determined (Figures 14-16), $\mathrm{E}_{24}=59.64$.

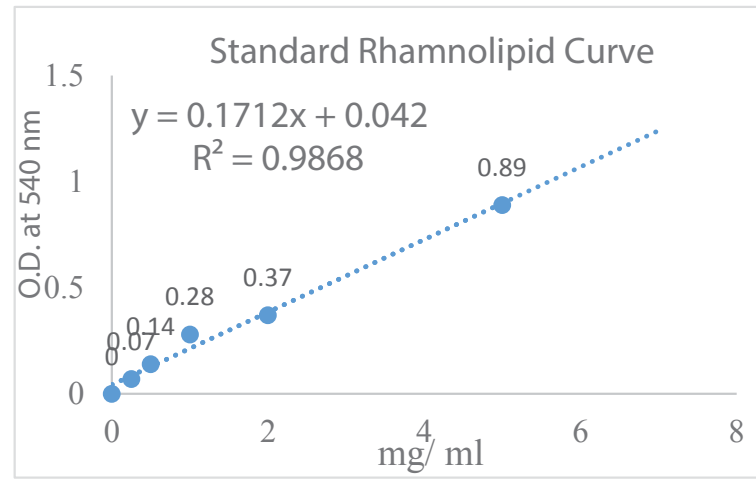

Graph 2: Standard rhamnolipid curve.
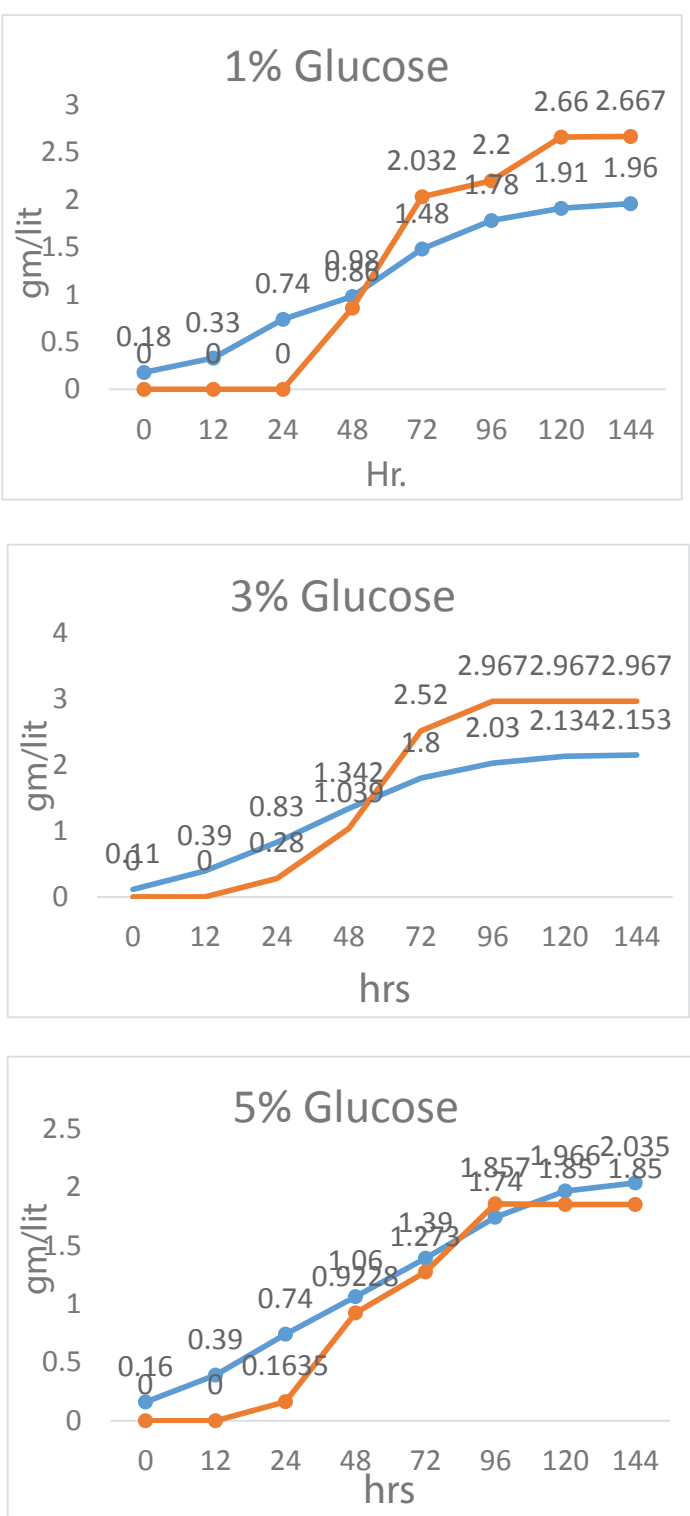

Graph 3.1- 3.3: Shows dry biomass concentration and rhamnolipid production at a glucose concentration of $1 \%, 3 \%$ and $5 \%$, where line shows dry biomass concentration and line shows rhamnolipid concentration. 

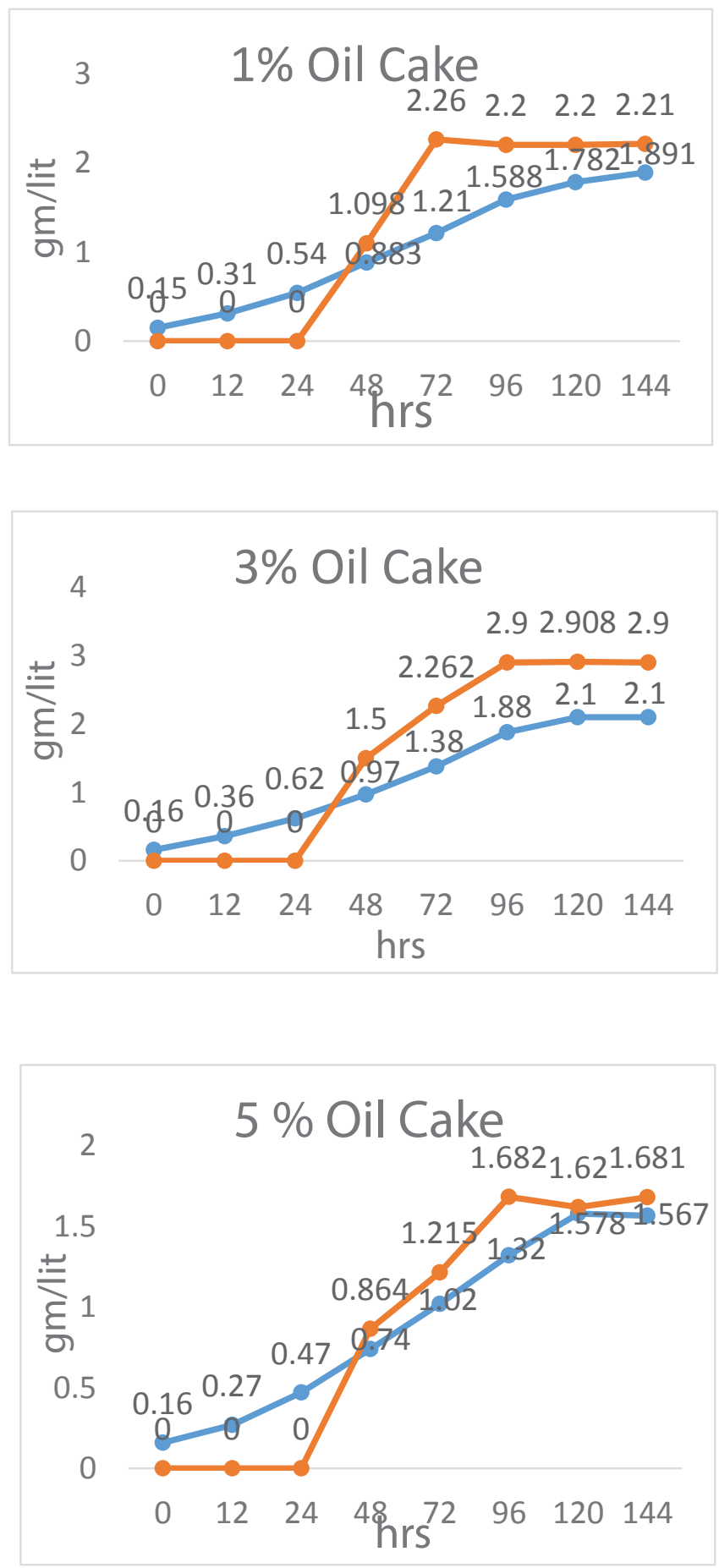

Graph 4.1- 4.3: Shows dry biomass concentration and rhamnolipid production at a soybean oil cake concentration of $1 \%, 3 \%$ and $5 \%$, where line shows dry biomass concentration and line shows rhamnolipid concentration.

Emulsification index stability: Emulsification index stability at various $\mathrm{pH}$ and temperatures is plotted in Graphs 10 and 11 .

\section{Heavy and toxic metal recovery}

The recovery of heavy $\mathrm{FeCl}_{3}, \mathrm{ZnSO}_{4}, \mathrm{~Pb}\left(\mathrm{NO}_{3}\right)_{2}$ was done at concentration $73 \%, 65 \%, 71 \%$ respectively and NF at concentration
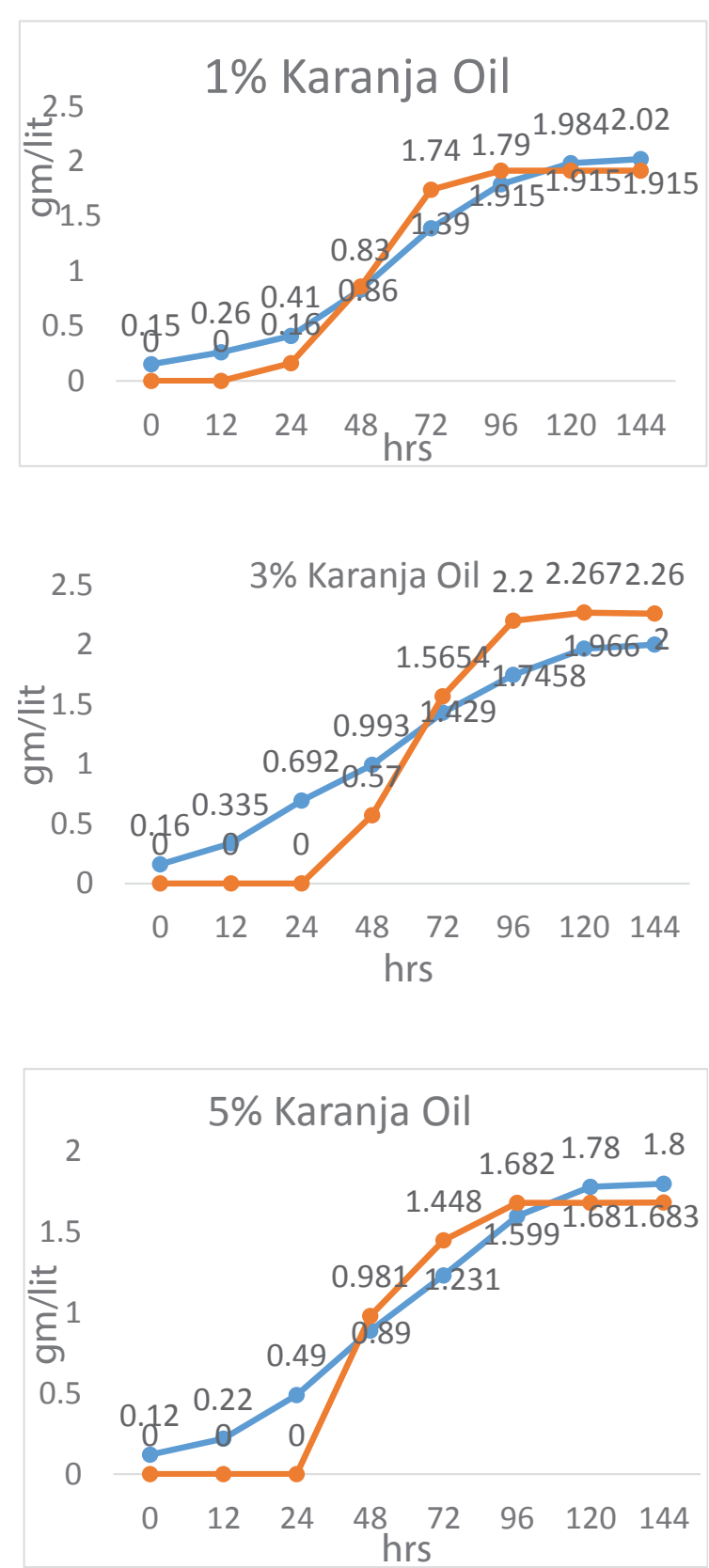

Graph 5.1- 5.3: Shows dry biomass concentration and rhamnolipid production at a karanja oil concentration of $1 \%, 3 \%$ and $5 \%$, where line shows dry biomass concentration and line shows rhamnolipid concentration.

43\% (Tables 6 and 7, Figures 17 and 18).

\section{Conclusion}

The results show that, the rhamnolipid was successfully produced from Pseudomonas aeruginosa MTCC 1688 strain. The strategic search for cheap and effective substrate ends in karanja oil and soybean oil cake, which shows effective and enhanced production of rhamnolipid, 


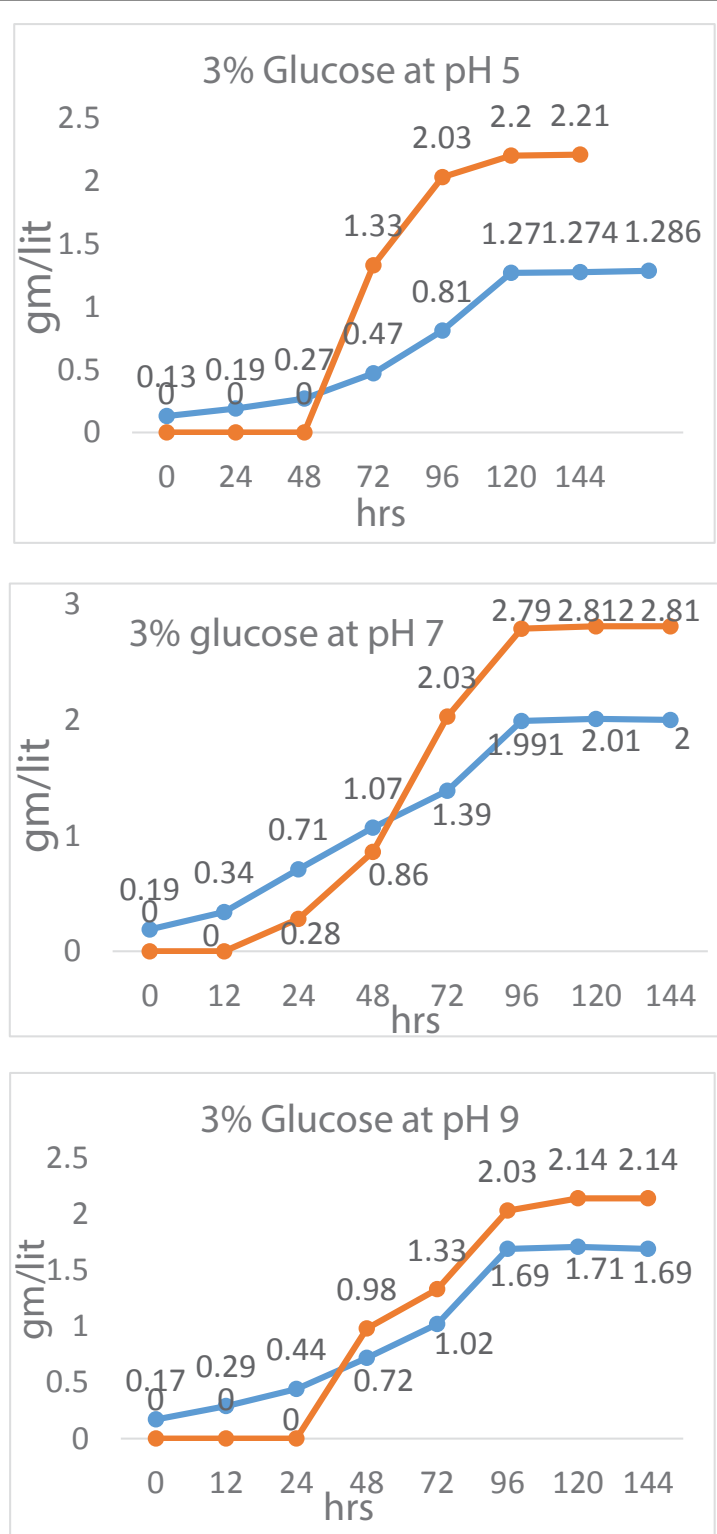

Graph 6.1- 6.3: Shows dry biomass concentration and rhamnolipid production at a $3 \%$ glucose concentration, at $\mathrm{pH} 5$ 7 and 9 respectively, where line shows dry biomass concentration and line shows rhamnolipid concentration.

at optimised $\mathrm{pH}$ of 7 and optimised concentration of 3\%, compared to the various past researches. The optimum yield in terms of substrate was observed as $3.609 \mathrm{gm} / \mathrm{lit}$ of rhamnolipid produced per $5.255 \mathrm{ml}$ of oil consumed, while yield in terms of biomass observed as $3.609 \mathrm{gm} /$ lit of rhamnolipid produced per $2.5 \mathrm{gm}$ of dry biomass. The chloroform:methanol extraction system was found to be the best solvent extraction system, where $83 \%$ of the rhamnolipid as recovered. The rhamnolipid was successfully applied for the heavy metals and toxic metals recovery, where rhamnolipid reduces heavy metal concentration to $73 \%, 65 \%, 71 \%$ for $\mathrm{FeCl}_{3} \mathrm{ZnSO}_{4} \mathrm{~Pb}\left(\mathrm{NO}_{3}\right)_{2}$ respectively, while $43 \%$ in the case of toxic metal i.e. $\mathrm{NaF}$. The produced rhamnolipid was found efficient in recovering $31 \%$ oil from oil sludge. Although rhamnolipid production has been intensively studied since the 1990's, rhamnolipids

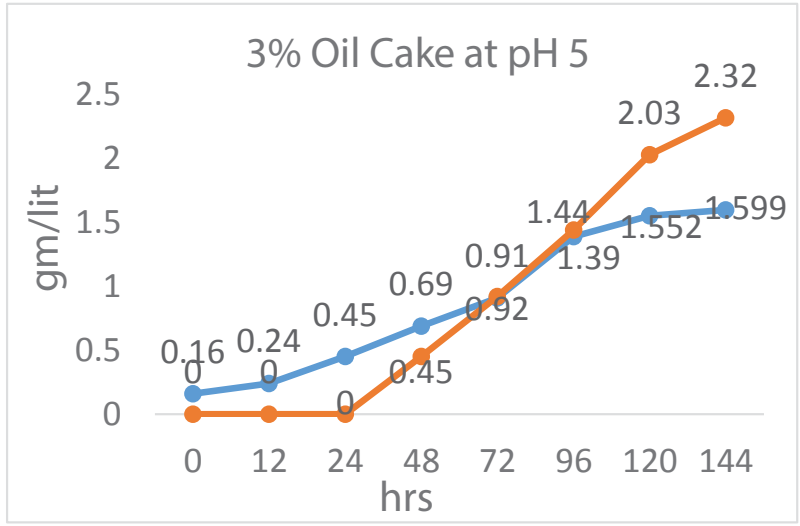

\section{$3 \%$ Oil Cake at pH 7}

3

2.532 .5342 .5

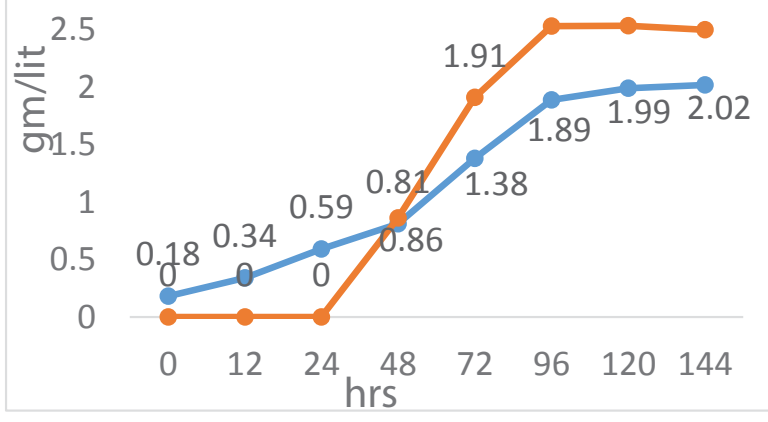

\section{3\% Oil Cake at pH 9}

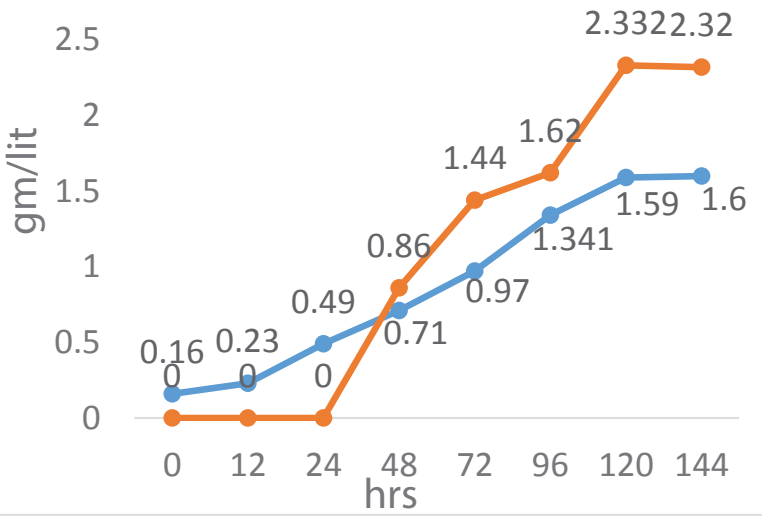

Graph 7.1-7.3: Shows dry biomass concentration and rhamnolipid production at a $3 \%$ soybean oil cake concentration, at $\mathrm{pH} 5,7$ and 9 respectively, where line shows dry biomass concentration and line shows rhamnolipid concentration.

have not widely succeeded in substituting synthetic surfactants; rather their use is restricted to specific applications where biocompatibility is required. The main reason for this situation can be found in the high costs for synthesis and downstream processing of rhamnolipids. The development of new production processes is the key issue in overcoming these economic obstacles. 
Citation: Pathaka AN, Nakhate PH (2015) Optimisation of Rhamnolipid: A New Age Biosurfactant from Pseudomonas aeruginosa MTCC 1688 and its Application in Oil Recovery, Heavy and Toxic Metals Recovery. J Bioprocess Biotech 5: 229 doi:10.4172/2155-9821.1000229
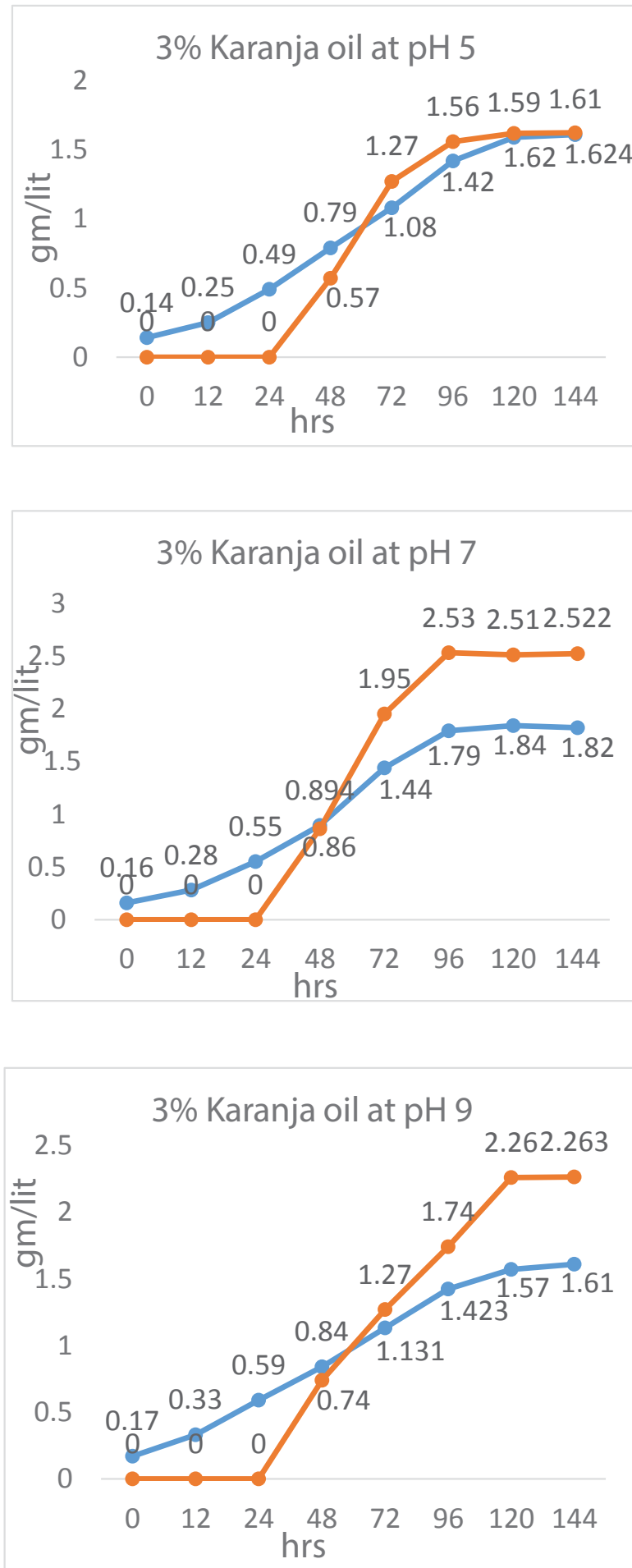

Graph 8.1- 8.3: Shows dry biomass concentration and rhamnolipid production at a $3 \%$ Karania nil roncentration, at $\mathrm{pH} 5,7$ and 9 respectivals whore line shows dry biomass concentration and line shows rhamnolipid concentration.
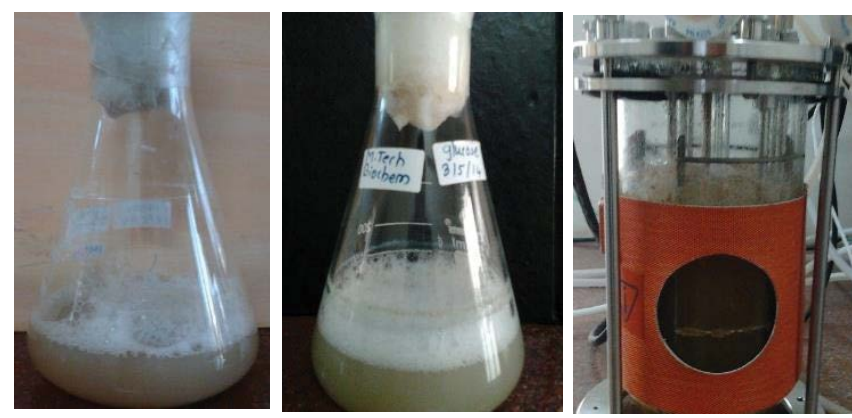

Figure 7: Foam formation during the fermentation.
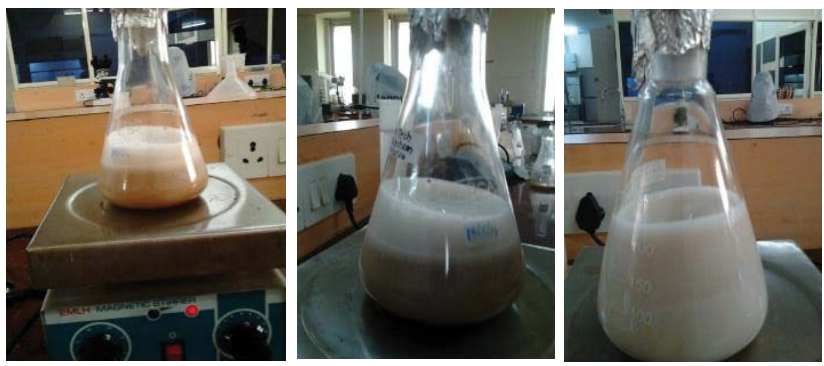

Figure 8: Foam formation using magnetic stirrer after the fermentation in order to enhance bio surfactant production.

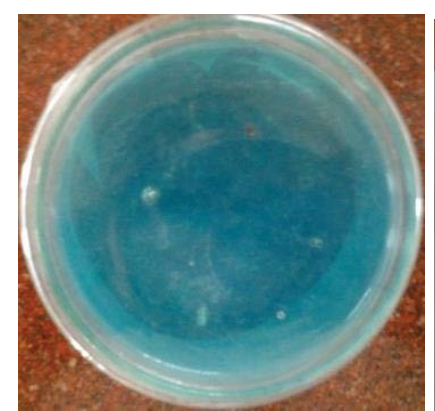

Agar Plate before Incubation

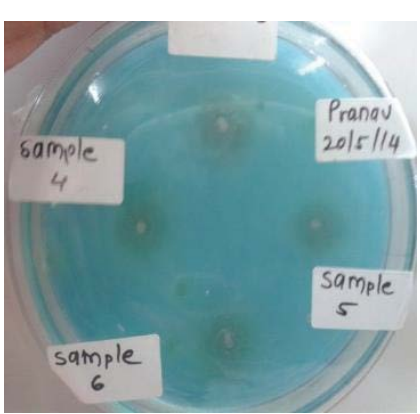

Agar Plate after 24 hrs Incubation
Figure 9: CTAB- methylene blue agar plate.

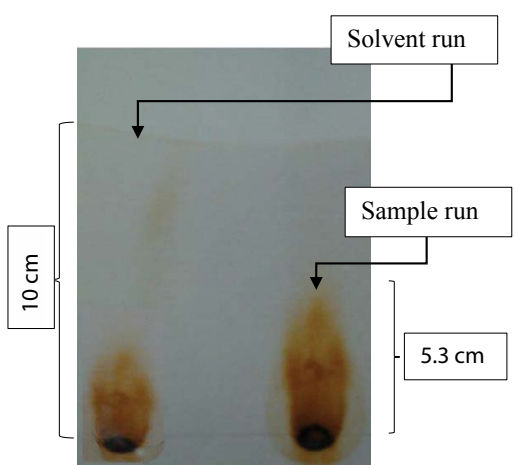

Figure 10: Paper chromatography result. 
Citation: Pathaka AN, Nakhate PH (2015) Optimisation of Rhamnolipid: A New Age Biosurfactant from Pseudomonas aeruginosa MTCC 1688 and its Application in Oil Recovery, Heavy and Toxic Metals Recovery. J Bioprocess Biotech 5: 229 doi:10.4172/2155-9821.1000229
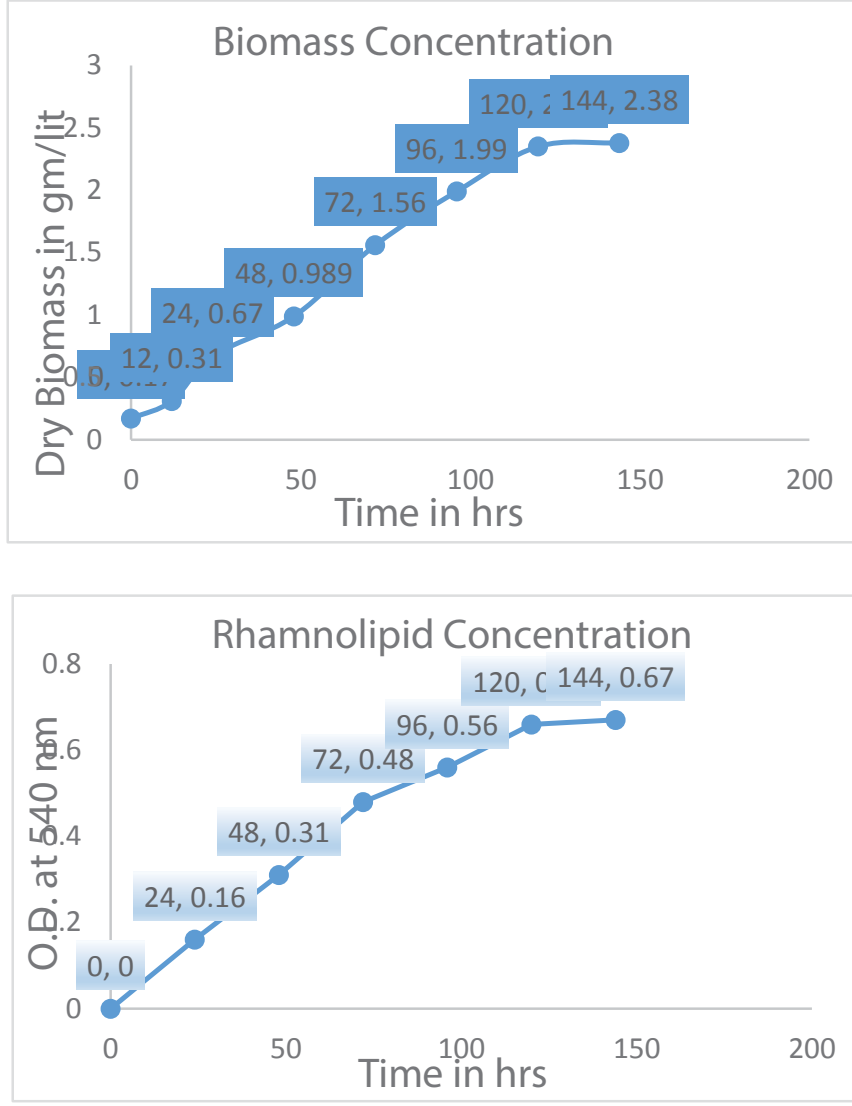

Graph 9.1- 9.3: Shows dry biomass concentration and rhamnolipid production at a $3 \%$ soybean oil cake concentration, at $\mathrm{pH} 5$ in fermenter.

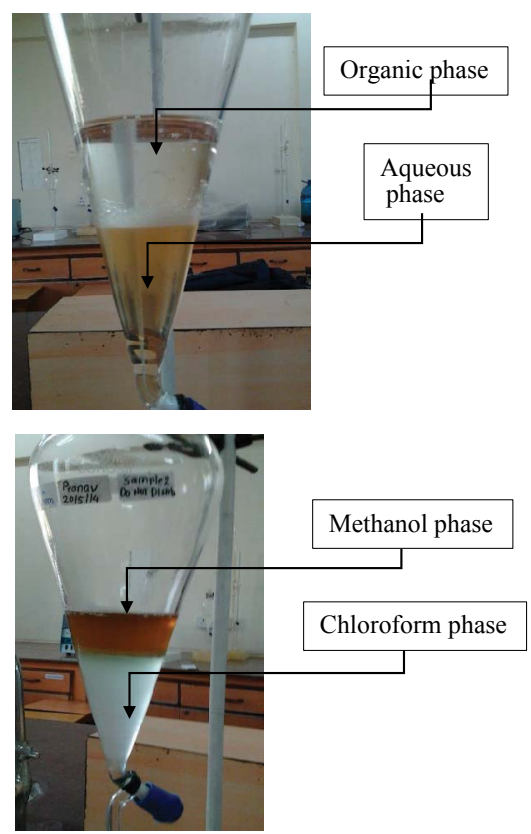

Figure 11: Solvent extraction using separating funnel with different extraction schemes

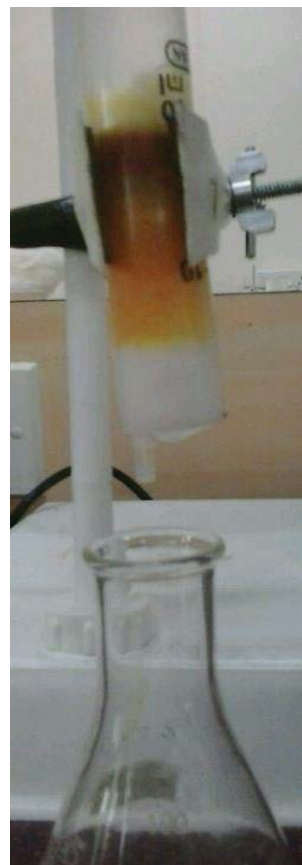

Figure 12: Column chromatography setup.

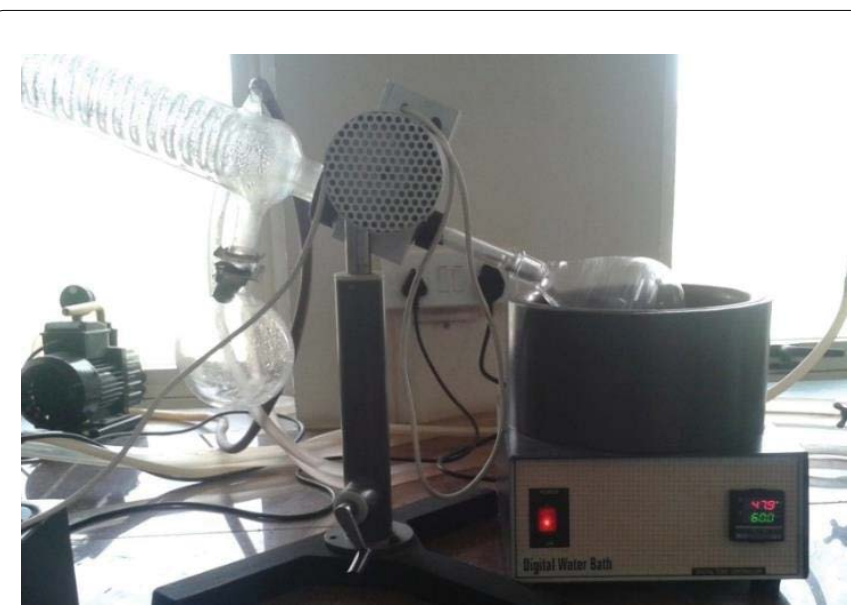

Figure 13: Rotary vacuum evaporator setup.

\begin{tabular}{|c|c|c|c|c|c|}
\hline S. No & Metal & $\begin{array}{c}\text { Wt. of Filter } \\
\text { paper } \\
\text { before } \\
\text { (gm) }\end{array}$ & $\begin{array}{c}\text { Wt. of Filter } \\
\text { paper after } \\
\text { filtration } \\
\text { and drying } \\
\text { (gm) }\end{array}$ & $\begin{array}{c}\text { Difference } \\
\text { (gm) }\end{array}$ & $\begin{array}{c}\text { Efficiency of } \\
\text { metal } \\
\text { recovery }\end{array}$ \\
\hline 1 & $\mathrm{FeCl}_{3}$ & 1.244 & 1.271 & 0.027 & $73 \%$ \\
\hline 2 & $\mathrm{ZnSO}$ & 1.273 & 1.308 & 0.035 & $65 \%$ \\
\hline 3 & $\mathrm{~Pb}\left(\mathrm{NO}_{3}\right)_{2}$ & 1.302 & 1.331 & 0.029 & $71 \%$ \\
\hline 4 & $\mathrm{NaF}$ & 1.242 & 1.285 & 0.043 & $43 \%$ \\
\hline
\end{tabular}

Table 6: Calculation table for heavy and toxic metal recovery. 


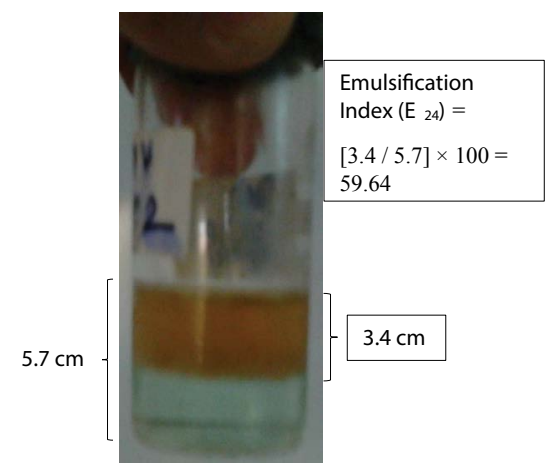

Figure14: Formation of emulsion.

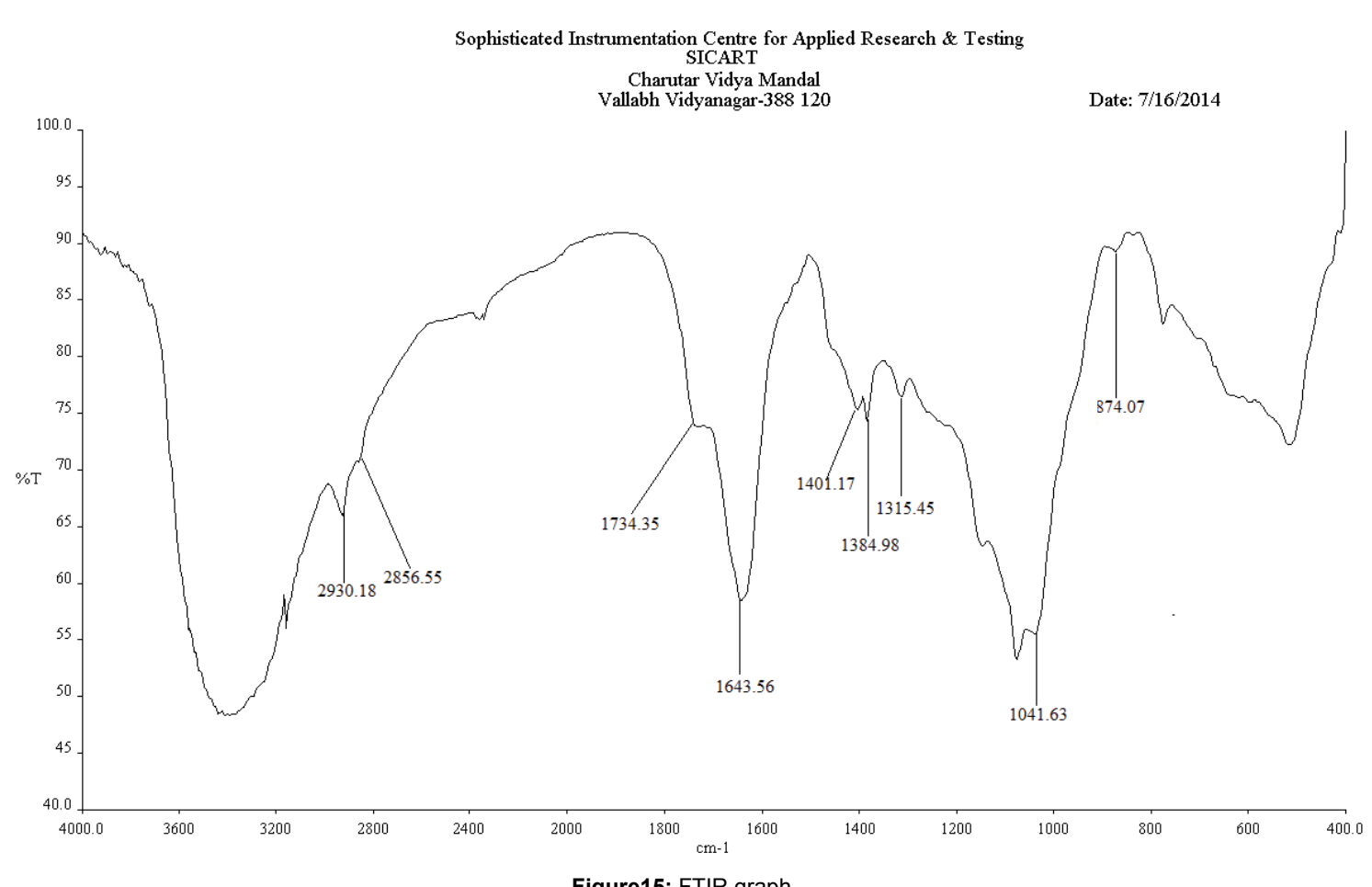

Figure15: FTIR graph.

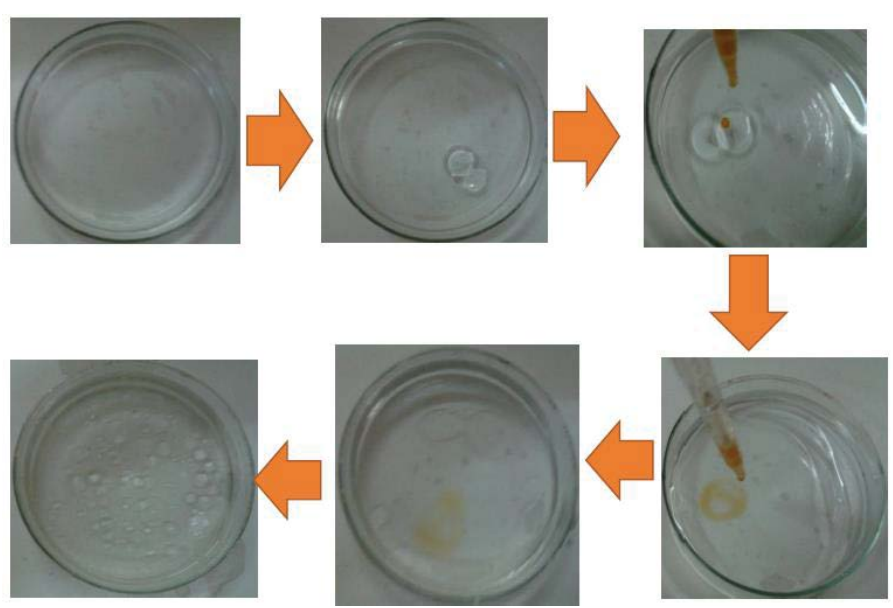

Figure 16: Formation of emulsion via oil spray technique. 

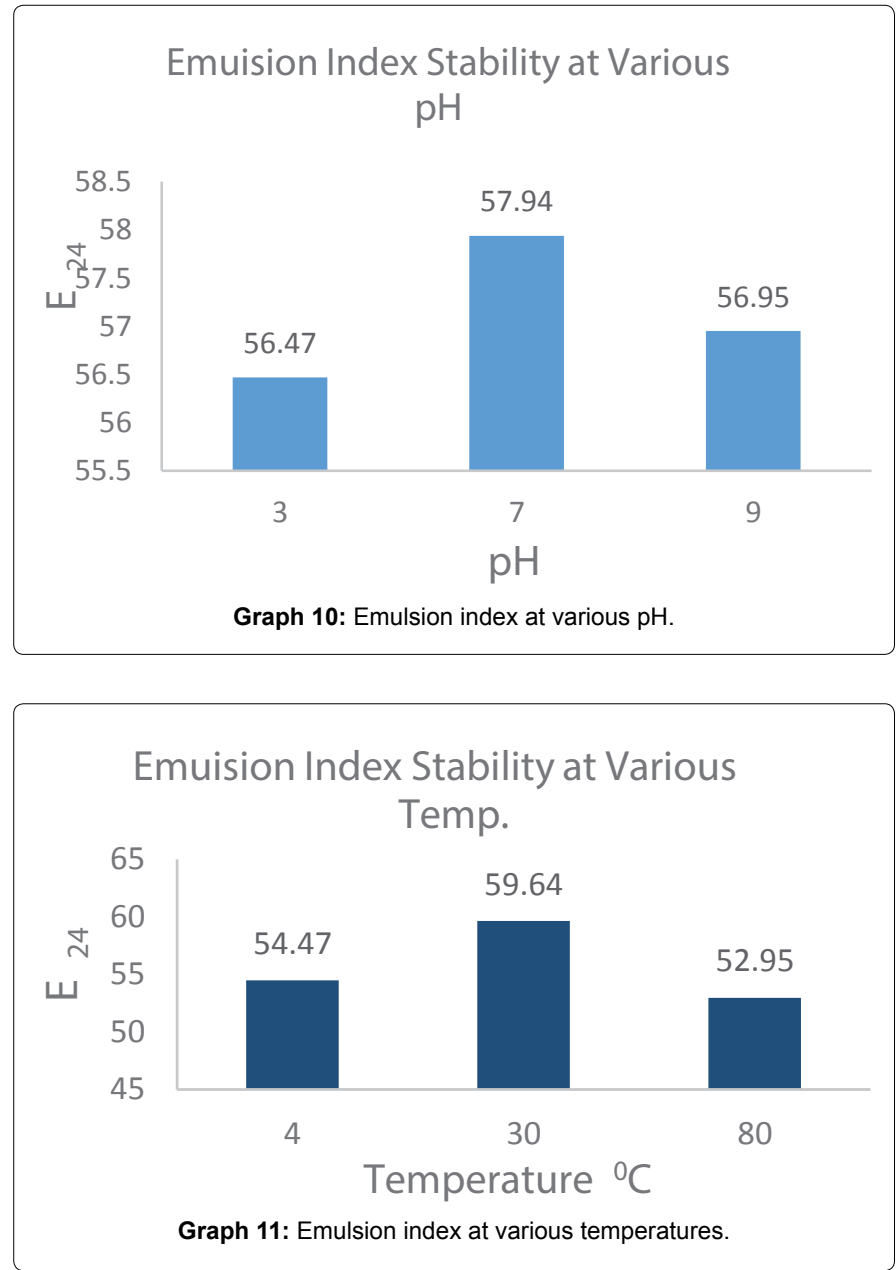

\begin{tabular}{|c|c|c|}
\hline S. & $\begin{array}{c}\text { Experimental } \\
\text { parameter }\end{array}$ & Value \\
\hline 1 & Amount of sand taken & $10 \mathrm{gm}$ \\
\hline 2 & Volume of oil added & $10 \mathrm{ml}$ \\
\hline 3 & Volume of RL added & $10 \mathrm{ml}$ \\
\hline 4 & Vortexing time & $5 \mathrm{~min}$ \\
\hline 5 & Centrifugation speed & $6000 \mathrm{rpm}$ \\
\hline 6 & Hexane used & $10 \mathrm{ml}$ \\
\hline 7 & Oil recovered & $3.1 \mathrm{ml}$ \\
\hline 8 & Percentage of oil & $31 \%$ \\
\hline & recovered & \\
\hline
\end{tabular}

Table 7: Percentage recovery of oil from sludge.
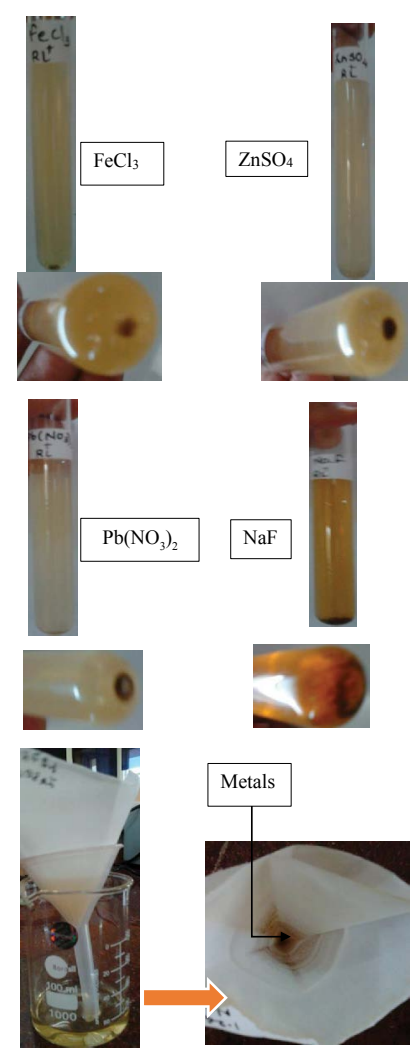

Figure 17: Heavy and toxic metal recovery process, showing recovery of $\mathrm{FeCl}_{3}, \mathrm{ZnSO}_{4}, \mathrm{~Pb}\left(\mathrm{NO}_{3}\right)_{2}$ and $\mathrm{NF}$ respectively

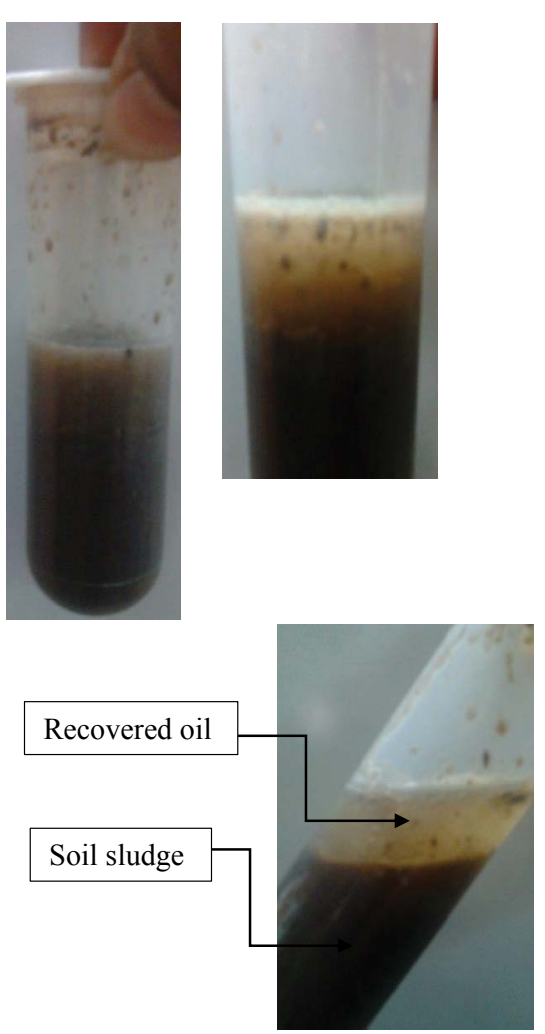

Figure 18: Oil recovery. 
Citation: Pathaka AN, Nakhate PH (2015) Optimisation of Rhamnolipid: A New Age Biosurfactant from Pseudomonas aeruginosa MTCC 1688 and its Application in Oil Recovery, Heavy and Toxic Metals Recovery. J Bioprocess Biotech 5: 229 doi:10.4172/2155-9821.1000229

Page 14 of 14

\section{References}

1. Al-Araji L, Abdul Rahman RNZR, Basri M, Salleh AB (2007) Microbial Surfactan - Miniriview. Asia Pac J Mol Biol Biotechnol 15: 99-105.

2. Benincasa M, Abalos A, Oliveira I, Manresa A (2004) Chemical structure, surface properties and biological activities of the biosurfactant produced by Pseudomonas aeruginosa LBI from soapstock. Antonie Van Leeuwenhoek 85: $1-8$.

3. Edser C (2008) Status of global surfactant markets. Focus on Surfactants 11 $1-2$.

4. Sharma D, Saharan BS, Chauhan N, Procha S, Lal S (2015) Isolation and functional characterization of novel biosurfactant produced by Enterococcus faecium. Springerplus 4: 4

5. Banat IM, Franzetti A, Gandolfi I, Bestetti G, Martinotti MG, et al. (2010) Microbial biosurfactants production, applications and future potential. Appl Microbiol Biotechnol 87: 427-444

6. Saharan BS, Sahu RK, Sharma D (2011) A Review on Biosurfactants: Fermentation, Current Developments and Perspectives. Genet Eng Biotechnol J 2011: GEBJ-29.

7. Šonc A, Grilc V (2004) Batch Foam Fractionation of Surfactants from Aqueous Solutions. Acta Chim Slov 5: 687-698.

8. Desai JD, Banat IM (1997) Microbial production of surfactants and their commercial potential. Microbiol Mol Biol Rev 61: 47-64.

9. Rikalovic MG, Gojgic-Cvijovic G, Vrvic MM, Karadžic I (2012) Production and characterization of rhamnolipids from Pseudomonas aeruginosa san-ai. J Serb Chem Soc 77: 27-42.

10. Mukherjee S, Das $P$, Sen $R$ (2006) Towards commercial production of microbial surfactants. Trends Biotechnol 24: 509-515.
11. Henkel M, Müller MM, Kügler JH, Lovaglio RB, Contiero J, et al. (2012) Rhamnolipids as biosurfactants from renewable resources: Concepts for nextgeneration rhamnolipid production. Process Biochem 47: 1207-1219.

12. Reis RS, Pacheco GJ, Pereira AG, Freire DMG (2013) Biosurfactants: Production and Applications. In: Chamy R, Rosenkranz F (eds). Agricultural and Biological Sciences. Biodegradation - Life of Science. InTech Open.

13. Zhi L, Xingzhong Y, Hua Z, Guangming Z, Zhifeng L, et al. (2013) Optimizing rhamnolipid production by Pseudomonas aeruginosa ATCC 9027 grown on waste frying oil using response surface method and batchfed Fermentation. $J$ Cent South Univ 20: 1015-1021.

14. Wadekar SD, Kale SB, Lali AM, Bhowmick DN, Pratap AP (2012) Utilization of sweetwater as a cost-effective carbon source for sophorolipids production by Starmerella bombicola (ATCC 22214). Prep Biochem Biotechnol 42: 125142

15. Cameotra SS, Makkar RS (1998) Synthesis of biosurfactants in extreme conditions. Appl Microbiol Biotechnol 50: 520-529.

16. Kannahi M, Sherley M (2012) Biosurfactant production by Pseudomonas putida and Aspergillus niger from oil contaminated site. IJCPS 3: 37-42.

17. Urum K, Pekdemir T, Copur M (2005) Screening of Biosurfactants for Crude Oi Contaminated Soil Washing. J Environ Engg Sci 4: 487-496

18. Pinto E, Aguiar AARM, Ferreira IMPLVO (2014) Influence of Soil Chemistry and Plant Physiology in the Phytoremediation of $\mathrm{Cu}, \mathrm{Mn}, \mathrm{Zn}$. Crit Rev Plant Sci 33: 351-373.

19. Shafiei Z, Abdul Hamid A, Fooladi T, Yusoff WMW (2014) Surface Active Components: Review. Current Research Journal of Biological Sciences 6: 8995. 